\title{
Equilibrium social insurance with policy-motivated parties
}

\author{
Philippe De Donder ${ }^{1}$ \\ University of Toulouse, GREMAQ-CNRS and IDEI \\ 21 allée de Brienne, 31000 Toulouse, France.
}

Jean Hindriks

CORE and Department of Economics, Université catholique de Louvain 34 Voie du Roman Pays, 1348 Louvain-la-Neuve, Belgium.

February 2007

${ }^{1}$ Corresponding author. Tel.: +33 561128 603; fax: +33 561128 637. E-mail address: dedonder@cict.fr 


\begin{abstract}
We study the political economy of social insurance with voters' heterogeneity on two dimensions: income and risk levels. Individuals vote over the extent of social insurance, which they can complement on the private market. We model political competition à la Wittman, with two parties maximizing the utility of their members. We obtain equilibrium policy differentiation with the Left party proposing more social insurance than the Right party. The Right party attracts the less risky and richer individuals, and the Left party attracts the more risky and poorer individuals. In equilibrium, each party is tying for winning. Unlike the median voter outcome, our equilibrium outcome depends on the whole income and risk distribution. Conditional on the risk distribution, more income inequality does not necessarily lead to higher demand for social insurance. In fact we find that more income polarization leads both parties to propose less social insurance. We also contrast our political equilibrium with the Rawlsian and utilitarian outcomes. Finally, we provide in the appendix a first try at calibrating the model with real data, using U.S. data from the PSID survey.
\end{abstract}

Keywords: electoral competition, endogenous parties, Wittman equilibrium, social insurance, adverse selection.

JEL classification: H23, H50 


\section{Introduction}

The Downsian model of two-party competition over a single dimension predicts party convergence to the median voter's most preferred policy if parties are motivated solely by winning the election and voters' preferences satisfy certain properties (single-peakedness or single-crossing mainly). While Downs(1951) has inspired a very fruitful literature on spatial competition, the Downsian model fails to predict the persistent party divergence we observe. Divergence between party positions is well documented in Alesina and Rosenthal (1995) and Poole and Rosenthal (1984a,1984b) for the US, Hofferbert and Budge (1992) for the UK and Hofferbert and Klingemann (1990) for Germany. Also, Mac Donald et al. (1991) show that Western European political parties exhibit a tendency toward polarized politics, with the absence of party position in the center of the distribution of voters' ideal points.

In this paper, we use a political economy model that results in party divergence. Following Wittman, we modify the standard Downsian model to permit parties to care both about winning elections and about policy. More precisely, political parties have policy preferences and adopt policy positions which trade off those preferences against their chance of winning the election. Unlike many other models that generate centrifugal forces, this approach generates divergence simply by making realistic assumptions about the nature of political parties and voters motivations. In particular, as Roemer (2007) points out, parties are inevitably associated with ideologies and their members have an influence in shaping policies.

In his seminal paper, Wittman (1973) assumes that parties are uncertain about the election results when choosing their platform and that they choose policies in order to maximize expected utility. However, Wittman (1973) does not explain where the party preferences come from, and makes no attempt to relate them to voters preferences. Later, Ortuño-Ortín and Roemer (2000) assume that parties maximize the expected utility of their members which consist of all the citizens who vote for this party (i.e., who prefer the policy proposed by this party to the one proposed by the other party). This was coined the endogenous Wittman equilibrium. Therefore, what political parties offer depends on who they attract and who they attract depends on what they offer. This is akin to the idea that citizens vote with their feet as well as in the voting booth. ${ }^{1}$ In their model, individuals with different income endowments vote over a proportional income tax rate to finance a public good. In stark contrast with the Downsian results, they obtain that the expected equilibrium tax rate does not coincide with the median voter outcome. Moreover, the expected tax rate is not increasing with

\footnotetext{
${ }^{1}$ See Baron (1993) and Caplin and Nalebuff (1997) for similar ideas.
} 
income inequality (as defined by the difference between mean and median income levels).

Our objective in this paper is to develop a political model where endogenously formed policy-motivated parties compete over the size of social insurance when there exists a possibility of substitution with private insurance. The reason for concentrating on social insurance is that it is a central source of disagreement among political parties in many countries. In our model, there are two reasons for supporting social insurance. The first reason is redistribution. Social insurance financing is usually income-related, which implies redistribution from rich to poor. Social insurance is also pooling different risk levels which implies redistribution from low-risk to high-risk individuals. In contrast, private insurance premia are not related to income but are related to risk, which eliminates either form of redistribution.

The second reason to support social insurance is efficiency. Contrary to many papers in the literature which assume perfect private insurance, ${ }^{2}$ we introduce adverse selection in the private insurance market. This generates insurance rationing and provides an efficiency argument for social insurance.

When voting over the level of social insurance, individuals know they can buy additional insurance on the private market. Following De Donder and Hindriks (2003), we adopt Yaari (1987)'s dual theory of choice under uncertainty where risk aversion does not require decreasing marginal utility of income, but is translated into a transformation of probabilities. This formulation, where attitudes towards risk and wealth are separated, allows us to obtain insights that could hardly be obtained with the expected utility model. However, there are two distinct features of this model compared to De Donder and Hindriks (2003). First, we depart from the Downsian median voter approach. Second, distortionary financing of social insurance generates interior preferences for social insurance and thus the need for topping up with private insurance.

A nice feature of our model is that the multi-dimensional types can be aggregated into a single dimensional type function which reflects differences in both income and risks. Hence individuals with different income and risk may have the same preference over social insurance. Using this type aggregator will prove useful to analyze voting outcomes. We then perform numerical simulations of the political equilibrium outcome. Our main objectives are, first, to compare the Wittman equilibrium with other allocations, such as the Downsian equilibrium, the Rawlsian and the utilitarian allocations and, second, to perform a comparative statics analysis with respect to variations in electoral uncertainty, distortions in taxation and the distribution of income (both its skewness and its polarization).

\footnotetext{
${ }^{2}$ See e.g., Blomqvist and Horn (1984), Rochet (1991), Cremer and Pestieau (1996), Gouveia (1997), and Petretto (1999).
} 
Our main results are as follows. With two-party competition, we obtain policy differentiation with the Left party proposing more social insurance and attracting the support of the poorer and riskier individuals and the Right party offering less social insurance to attract the richer and safer individuals. Parties pick a policy equidistant from the median most preferred policy, with each party tying for winning the election. Policy choices are strategic complements with one party offering more social insurance when the other does. This is due to the endogenous change in parties' memberships as policy choices change. The amount of social insurance that the parties choose to offer in equilibrium depends on the whole income distribution rather than simply on the gap between the median and mean income levels. Increasing the skewness of the income distribution leads both parties to offer more social insurance, while increasing income polarization reduces the amount of social insurance each party will offer. Income polarization can take either the form of a mean-preserving shift to the tails of the income distribution or increased spread of the income distribution. We also compare the political equilibrium outcome to the Rawlsian and utilitarian outcomes. We find that both parties always propose less social insurance than the Rawlsian level. The utilitarian outcome differs in general from the expected endogenous Wittman equilibrium outcome. When risks and income are not correlated, with a uniform distribution of risks and a positively skewed distribution of income, we obtain that the expected endogenous Wittman equilibrium rate is larger than the utilitarian level.

Finally, we provide a simple calibration of our model to U.S. data on health insurance and compute the equilibrium position of each political party.

The paper is organized as follows. Section 2 presents the economic model. Section 3 describes the individual preferences for social insurance given the possibility of topping up with private insurance. Section 4 presents the political competition model and the equilibrium concept. Section 5 contains the results. We calibrate the model to US data on health insurance in an appendix.

\section{The model}

We describe briefly the economic model which is adapted from De Donder and Hindriks (2003) to allow for distortionary financing of social insurance. There is a continuum of individuals who differ in income $w \in[\underline{w}, \bar{w}]$ and risk $\theta \in[\underline{\theta}, \bar{\theta}]$ continuously distributed according to a joint distribution function $H(w, \theta)$, with the frequency distribution denoted by $h(w, \theta)$. The marginal distribution of risks in the population is denoted by $F(\theta)$, with mean $\theta_{\mu}=\int_{\underline{\theta}}^{\bar{\theta}} \theta d F(\theta)$ and median $\theta_{m}=F^{-1}(1 / 2)$. The risk is the probability of incurring a damage of fixed value (normalized to one). Income levels are 
distributed according to the marginal distribution function $G(w)$ with mean $w_{\mu}=\int_{w}^{\bar{w}} w d G(w)$ and median $w_{m}=G^{-1}(1 / 2)$.

Individual choice under risk is dual to the expected utility theory in the sense that it is linear in wealth but non linear in probabilities (see Yaari, 1987). We use this formulation to separate attitude towards risk from attitude towards wealth and to circumvent the problem that redistribution of income through social insurance would influence the demand for private insurance. With the dual theory, utility is linear in income and risk aversion translates into a transformation of probabilities that puts extra weight on bad outcomes and less weight on good outcomes. The insurance contracts consist of a premium $\pi$ and a coverage rate $\delta \in[0,1]$ which is the proportion of the fixed damage reimbursed. More precisely, the utility derived by an individual of type $(w, \theta)$ from an insurance contract $(\pi, \delta)$ is

$$
u(\pi, \delta, w, \theta)=w-\pi-(1+\alpha) \theta(1-\delta)
$$

where $\alpha \geq 0$ is a risk aversion parameter. In words, the individual overestimates by a factor $\alpha$ the probability of the bad event occurring, which translates into the higher weight $(1+\alpha) \theta$ put on the residual damage $(1-\delta)$.

There are two sorts of insurance. The compulsory social insurance offers coverage $\delta$ and is financed through proportional income taxation, with the tax rate $\tau \in[0,1]$ set to equate tax revenue to expected social insurance payout. However, taxation is distortionary with a deadweight loss that is approximately a quadratic function of the tax rate. Alternatively, with a quadratic distortion, increasing the social insurance coverage rate requires to raise more than proportionally the tax rate. In fact the tax rate can be written as a quadratic function of the social insurance rate. Letting $\eta \geq 0$ denote the deadweight loss parameter from taxation, the tax rate $\tau$ solves

$$
\begin{aligned}
\tau w_{\mu} & =\delta \theta_{\mu}+\eta \delta^{2} \theta_{\mu} \\
& =(1+\eta \delta) \delta \theta_{\mu}
\end{aligned}
$$

Thus for $\eta=0$, as in De Donder and Hindriks (2003), there is no distortion and the tax rate is proportional to expected payout.

Individuals can supplement social insurance with private insurance. Individual risks are private information, and insurance firms only observe the marginal distribution $F(\theta)$. Faced with this adverse selection problem, firms separate risk types by offering different coverage rates at different prices. Perfect competition ensures zero expected profits with actuarially fair-priced insurance. Formally, if $\delta$ is the social insurance coverage and $\delta(\theta)$ (with $0 \leq \delta(\theta) \leq 1$ ) is the total coverage for type $\theta$, then the extra private coverage $\delta(\theta)-\delta \geq 0$ is purchased at the fair price $\theta$ and satisfies the standard incentive compatibility constraints. In that case, the utility obtained by type $(w, \theta)$ with the social insurance rate $\delta$ and tax rate $\tau$ is

$$
v(\delta, w, \theta)=(1-\tau) w-\theta(\delta(\theta)-\delta)-(1+\alpha) \theta(1-\delta(\theta)),
$$


where $\tau$ is given by (2) and where $1-\delta(\theta) \geq 0$ denotes the residual risk. The necessary local incentive compatibility (IC) constraint implies that no type $\theta$ can benefit from claiming to be of a different arbitrarily close type $\widehat{\theta}$. That is,

$$
\left[\frac{\partial v(\delta, w, \theta)}{\partial \hat{\theta}}\right]_{\hat{\theta} \rightarrow \theta}=\alpha \theta \delta^{\prime}(\theta)-(\delta(\theta)-\delta)=0 \quad \forall \theta
$$

The reader can check from Mailath (1987) that the function (3) implies that the local IC constraints (4) are not only necessary but also sufficient to characterize the separating equilibrium coverage rate $\delta(\theta)$. Solving (4), we obtain

$$
\delta^{\prime}(\theta)=\frac{\delta(\theta)}{\alpha \theta}-\frac{\delta}{\alpha \theta} \quad \forall \theta
$$

which, together with the optimality condition $\delta(\bar{\theta})=1$, gives the unique solution

$$
\delta(\theta)-\delta=(1-\delta)(\theta / \bar{\theta})^{1 / \alpha} .
$$

Equation (5) shows that, whatever the social insurance coverage rate $\delta<1$, all individuals except $\bar{\theta}$ are offered less than full coverage. This is due to the adverse selection on the private market. More precisely, the first best solution where all individuals buy full coverage on the private market at their own actuarially fair price cannot be an equilibrium, because high risk (and thus high price) individuals would rather buy the contracts intended for low risk (and low price) agents. To induce each buyer to separate and buy the contract designed for him, private insurers decrease the coverage rate aimed at lower risk individuals. By doing so, they prevent high risk individuals from buying the cheaper contracts designed for lower risk agents. Equation (5) also shows that total coverage increases with social insurance coverage, $\partial \delta(\theta) / \partial \delta>0$ (except of course for the highest risk $\theta=\bar{\theta}$ who gets full coverage in equilibrium). In other words, social insurance does not fully crowd out private insurance. The reason for this result is that, with adverse selection, the pooling social insurance cross-subsidizes risk levels and relaxes incentive constraints on the private insurance market. Observe also that private insurance is not affected in equilibrium by the tax distortion from the social insurance system. This is due to the absence of income effect in the demand for insurance with the dual theory of choice under risk.

Using (5) and (3), we obtain the indirect utility function

$$
\begin{aligned}
v(\delta, w, \theta)= & (1-\tau) w-\theta(1-\delta)(\theta / \bar{\theta})^{1 / \alpha} \\
& -(1+\alpha) \theta\left(1-(1-\delta)(\theta / \bar{\theta})^{1 / \alpha}-\delta\right) \\
= & (1-\tau) w-(1-\delta)(1+\varphi(\alpha, \theta)) \theta
\end{aligned}
$$

where

$$
\varphi(\alpha, \theta) \equiv \alpha\left(1-(\theta / \bar{\theta})^{1 / \alpha}\right) \geq 0
$$


is the efficiency gain from social insurance for type $\theta$ as measured by the extra coverage evaluated by the risk aversion parameter $\alpha>0$.

\section{$3 \quad$ Type aggregator and policy preferences}

To understand how citizens vote over social insurance, we first show that the two dimensions of individual preferences (i.e., income and risk) can be aggregated into a single dimensional type.

Differentiating the payoff function (6) with respect to $\delta$ while making use of (2), we get

$$
\frac{\partial v(\delta, w, \theta)}{\partial \delta}=\theta(1+\varphi(\alpha, \theta))-w(1+2 \eta \delta) \theta_{\mu} / w_{\mu}
$$

and $\partial^{2} v(\delta, w, \theta) / \partial \delta^{2}<0$ for $\eta>0$, so that the payoff function is concave with respect to $\delta$ for all $(w, \theta)$. With $\eta=0$, we have linear preferences over $\delta$ as in De Donder and Hindriks (2003). Define

$$
t(w, \theta)=(1+\varphi(\alpha, \theta)) \frac{\theta}{w} .
$$

We refer to this function as a type aggregator which is decreasing in $w$ and increasing in $\theta$. Low-types $t$ include rich and low risk individuals whereas high-types $t$ are comprised of poor and high risk individuals. Using this type aggregator $t$ and slightly abusing notation, we have

$$
\frac{\partial v(\delta, t(w, \theta))}{\partial \delta}=\left[t(w, \theta)-(1+2 \eta \delta) \frac{\theta_{\mu}}{w_{\mu}}\right] w
$$

Let $\underline{t} \equiv \theta_{\mu} / w_{\mu}$ and $\bar{t} \equiv(1+2 \eta) \underline{t}$, then the most-preferred social insurance rate of type $t(w, \theta)$ is given by

$$
\delta^{*}(t(w, \theta))=\left\{\begin{array}{cc}
0 & \text { for } t(w, \theta) \leq \underline{t} \\
\frac{w_{\mu} / \theta_{\mu}}{2 \eta}\left[t(w, \theta)-\frac{\theta_{\mu}}{w_{\mu}}\right] & \text { for } \underline{t}<t(w, \theta)<\bar{t} \\
1 & \text { for } t(w, \theta) \geq \bar{t}
\end{array}\right.
$$

Individual preference over social insurance depends on own income and risk relative to the average in the economy. The utility function is everywhere decreasing on $\delta \in[0,1]$ for low- $t$ individuals with $t(w, \theta) \leq \underline{t}$, everywhere increasing for high- $t$ individuals with $t(w, \theta) \geq \bar{t}$ and exhibits an interior maximum for other individuals with utility symmetry around the maximum. Moreover, for interior preferences, the preferred social insurance rate is increasing with $t$; so individuals can be put in a transitive order. This is due to the fact that those with higher $t$ benefit more from social insurance, since with high risk they pay less than the fair price and with lower income 
they pay less than the average income. Note that higher risk aversion increases the efficiency gain from social insurance, which increases $t$ and shifts up the demand for social insurance of everybody. Conversely, the distortion parameter $\eta$ is scaling down the demand for social insurance of everybody. Note also that $\underline{t}=\bar{t}$ when $\eta=0$ leading to $\delta^{*}(t(w, \theta))=\{0,1\}$ : individuals have corner preferences when there is no distortion. Figure 1 illustrates the aggregation of income and risk into the single dimensional type to reflect voters' preferences over social insurance. Figure 1 has been drawn for a uniform distribution of income on $[0, \bar{w}]$ and a uniform distribution of risk on $[0, \bar{\theta}]$ with $\eta>0$ so that $t(\bar{w}, \bar{\theta})=\underline{t}$ and the median type $t_{m}$ satisfies $\underline{t}<t_{m}<\bar{t}$.

\section{[insert figure 1]}

It will prove helpful later on to determine how voters partition themselves when they are given the choice between two social insurance rates, $\delta^{L}$ and $\delta^{R}$ with $\delta^{L} \neq \delta^{R}$. This partition is given by the critical type $t$ who is indifferent between $\delta^{L}$ and $\delta^{R}$, that is

$$
t^{\circ}\left(\delta^{L}, \delta^{R}\right)=\frac{\theta_{\mu}}{w_{\mu}}\left(1+\eta\left(\delta^{L}+\delta^{R}\right)\right) .
$$

Without loss of generality suppose that $\delta^{L}>\delta^{R}$, then single-peakedness of the utility function implies that all those with type $t(w, \theta)>t^{\circ}\left(\delta^{L}, \delta^{R}\right)$ prefer $\delta^{L}$ while those with type $t(w, \theta)<t^{\circ}\left(\delta^{L}, \delta^{R}\right)$ prefer $\delta^{R}$. The threshold type is increasing in both $\delta^{L}$ and $\delta^{R}$.

By the median voter theorem, the Condorcet winner (denoted by $\delta_{m}$ ) is the social insurance rate preferred by the individuals with the median type, $t_{m}$. This coverage rate is the equilibrium of a Downsian electoral competition game between two political parties only interested in winning the elections. We now turn to the description of the non-Downsian political competition model we use.

\section{Wittman political competition}

We consider two political parties (say $L$ and $R$ ) competing for votes in an election. Parties simultaneously choose a social insurance rate as their policy choice. The party with most votes wins the election and is committed to implement its policy. With two parties, there is no incentive for strategic voting: each citizen votes for the party proposing the policy closer to her most-preferred policy. Political parties are non-Downsian in the sense that they care about the policy preference of their constituency (defined as the set of citizens who vote for them). 
Without electoral uncertainty, the assumption that parties are policy motivated does not change the convergence result to the Condorcet winner found in Downs model. This is due to the fact that, to have any impact on the implemented policy, a party must win the election and thus propose the Condorcet winner (if it exists), regardless of its policy preferences (see Roemer, 2001). To allow parties to effectively express their policy preferences, we introduce uncertainty in the electoral process. This uncertainty, together with policy-motivated parties, gives rise to the following trade-off: by departing from the Condorcet winner, a party decreases its chances of being elected but brings its policy closer to what its members prefer.

We denote by $p\left(\delta^{L}, \delta^{R}\right)$ the proportion of individuals preferring $\delta^{L}$ to $\delta^{R}$. Assuming that $\delta^{L}>\delta^{R}$, and using (10), we obtain that

$$
p\left(\delta^{L}, \delta^{R}\right)=\int_{t(w, \theta) \geq t^{\circ}\left(\delta^{L}, \delta^{R}\right)} d H(w, \theta),
$$

We assume that this proportion does not translate into the exact same proportion of votes, because at the time of proposing their policy, parties ignore which citizens will show up at the voting booth. More precisely, we use the "error-distribution model of uncertainty" proposed by Roemer (2001), where both parties believe that the proportion of votes effectively cast in favor of $\delta^{L}$ belongs to the interval $p\left(\delta^{L}, \delta^{R}\right) \pm \Delta$ for some $\Delta>0$ and is distributed uniformly on this interval. Thus, the probability that $\delta^{L}$ defeats $\delta^{R}$ is

$$
q\left(\delta^{L}, \delta^{R}\right)=\left\{\begin{array}{ccc}
0 & \text { if } p\left(\delta^{L}, \delta^{R}\right)+\Delta \leq 1 / 2 \\
& \frac{p\left(\delta^{L}, \delta^{R}\right)+\Delta-1 / 2}{2 \Delta} & \text { otherwise } \\
1 & & \text { if } p\left(\delta^{L}, \delta^{R}\right)-\Delta \geq 1 / 2
\end{array}\right.
$$

The probability that $\delta^{L}$ defeats $\delta^{R}$ is a continuous function of the policy pair. Party $L$ defeats party $R$ with probability $q\left(\delta^{L}, \delta^{R}\right)$ and is defeated by party $R$ with probability $r\left(\delta^{L}, \delta^{R}\right)=1-q\left(\delta^{L}, \delta^{R}\right)$.

We assume as in Roemer(2001) that parties maximize the utility of their constituents. The introduction of electoral uncertainty means that voters evaluate lotteries - i.e., the prospect of getting policy $\delta^{L}$ with probability $q\left(\delta^{L}, \delta^{R}\right)$ and policy $\delta^{R}$ with probability $r\left(\delta^{L}, \delta^{R}\right)$. Parties, who represent voters, use the same dual preferences as their members to evaluate this lottery - i.e., they overweight the probability of the bad event occurring. Since party members by definition prefer the policy proposed by their party to the policy proposed by the other party, each party's members overweigh its probability of losing the elections. We assume that they overweigh the probability of losing the election by the risk aversion parameter $\alpha_{p}>0$. Note that the electoral probability transformation is distinct from the other probability transformation on the insurance market. We thus have a distinct risk aversion parameter, $\alpha_{p}$, on the political market which need not take the same value as the risk aversion parameter $\alpha$, on the insurance market. 
An Endogenous Parties Wittman Equilibrium is a policy pair such that each party is maximizing the average utility of its members and parties' memberships are optimal given these policy choices. Formally,

Definition 1 An Endogenous Parties Wittman Equilibrium (EPWE) is a pair $\left(\delta^{L}, \delta^{R}\right) \in[0,1] \times[0,1]$ such that

$\delta^{L}=\arg \max \left(1+\alpha_{p}\right) r\left(\delta^{L}, \delta^{R}\right) V^{L}\left(\delta^{R}\right)+\left[1-\left(1+\alpha_{p}\right) r\left(\delta^{L}, \delta^{R}\right)\right] V^{L}\left(\delta^{L}\right)$,

$\delta^{R}=\arg \max \left(1+\alpha_{p}\right) q\left(\delta^{L}, \delta^{R}\right) V^{R}\left(\delta^{L}\right)+\left[1-\left(1+\alpha_{p}\right) q\left(\delta^{L}, \delta^{R}\right)\right] V^{R}\left(\delta^{R}\right)$,

with the utility function of each party

$$
\begin{aligned}
V^{L}(\delta) & =\int_{t(w, \theta) \geq t^{\circ}\left(\delta^{L}, \delta^{R}\right)} v(\delta, t(w, \theta)) d H(w, \theta) ; \\
V^{R}(\delta) & =\int_{t(w, \theta)<t^{\circ}\left(\delta^{L}, \delta^{R}\right)} v(\delta, t(w, \theta)) d H(w, \theta)
\end{aligned}
$$

where the threshold type $t^{\circ}\left(\delta^{L}, \delta^{R}\right)$ is given by equation (10).

The first-order conditions for a Wittman equilibrium policy pair $\left(\delta^{L}, \delta^{R}\right)$ are

$$
\begin{aligned}
& {\left[1-\left(1+\alpha_{p}\right) r\left(\delta^{L}, \delta^{R}\right)\right] \frac{\partial V^{L}\left(\delta^{L}\right)}{\partial \delta^{L}}-\left[V^{L}\left(\delta^{L}\right)-V^{L}\left(\delta^{R}\right)\right]\left(1+\alpha_{p}\right) \frac{\partial r\left(\delta^{L}, \delta^{R}\right)}{\partial \delta^{L}}=0,} \\
& {\left[1-\left(1+\alpha_{p}\right) q\left(\delta^{L}, \delta^{R}\right)\right] \frac{\partial V^{R}\left(\delta^{R}\right)}{\partial \delta^{R}}-\left[V^{R}\left(\delta^{R}\right)-V^{R}\left(\delta^{L}\right)\right]\left(1+\alpha_{p}\right) \frac{\partial q\left(\delta^{L}, \delta^{R}\right)}{\partial \delta^{R}}=0 .}
\end{aligned}
$$

The marginal effect of a change in the coverage rate proposed by one party is twofold. First, it has a direct effect on the utility of the party's members (for a fixed membership). Second, it changes the probability of winning the election. The direct impact is given by the first term and measures variations in the utility of the party's members while maintaining the probability of winning constant. The indirect impact is measured by the second term, where the increase in utility from having one's party policy implemented rather than the other's is multiplied by the variation in the probability of winning. Both parties will then compromise between increasing their probability of winning the election and adopting a policy closer to what their members prefer, which will prevent them from proposing the Condorcet winning option.

\section{Results}

We are now in a position to compute the Wittman equilibria. The first-order conditions are too complex to obtain analytical results, so we will resort to 
numerical results. We take as the benchmark the case where the political $\left(\alpha_{p}\right)$ and the economic $(\alpha)$ risk aversion parameters are both equal to 0.1. Table 1 reports the Wittman equilibria when $w$ and $\theta$ are independently and uniformly distributed, with support $[0,2 / 3]$ for $\theta$ and $[0,4]$ for $w$. Results are given for three levels of the distortion parameter $\eta \in\{0.1,0.3,0.5\}$ and uncertainty $\Delta \in\{0.001,0.01,0.03\}$. For each configuration of parameters, the table reports the Wittman equilibrium policy pair $\left(\delta^{L}, \delta^{R}\right)$, and the median voter outcome, $\delta_{m}=\delta^{*}\left(t_{m}\right)$.

Table 1: Equilibrium with uniformly and independently distributed income

\begin{tabular}{|c|c|c|c|c|}
\hline$\eta$ & $\Delta$ & $\delta^{L}$ & $\delta^{R}$ & $\delta_{m}=\delta^{U}$ \\
\hline 0.1 & 0.03 & $65.81 \%$ & $17.55 \%$ & \multirow{3}{*}{$41.68 \%$} \\
\hline & 0.01 & $50.39 \%$ & $33.09 \%$ & \\
\hline & 0.001 & $42.55 \%$ & $40.78 \%$ & \\
\hline 0.3 & 0.03 & $21.93 \%$ & $5.85 \%$ & \multirow{3}{*}{$13.89 \%$} \\
\hline & 0.01 & $16.80 \%$ & $11.03 \%$ & \\
\hline & 0.001 & $14.18 \%$ & $13.59 \%$ & \\
\hline 0.5 & 0.03 & $13.17 \%$ & $3.51 \%$ & \multirow{3}{*}{$8.34 \%$} \\
\hline & 0.01 & $10.08 \%$ & $6.62 \%$ & \\
\hline & 0.001 & $8.51 \%$ & $8.16 \%$ & \\
\hline
\end{tabular}

The Wittman equilibrium outcome involves policy differentiation. The larger the value of $\Delta$, the greater the electoral uncertainty and the more differentiated the equilibrium policies. Intuitively, more uncertainty means that it is less electorally costly for the parties to depart from the Condorcet winner by moving closer to their members' preferred policy. For any $\Delta>0$, the equilibrium policy pair satisfies $\delta^{L}>\delta_{m}>\delta^{R}$ with party $L$ representing poor/high risk voters who want higher coverage and party $R$ representing rich/low risk voters who want lower coverage. Conversely, the equilibrium policy of either party converges to the median voter outcome, $\delta_{m}$, as the electoral uncertainty tends to zero. Unsurprisingly, both parties propose less coverage in equilibrium as the degree of distortion $\eta$ of social insurance increases, since everyone then wants less social insurance. Finally, increasing political risk aversion ${ }^{3}$ also reduces policy differentiation because voters dislike the uncertain policy outcome, which forces both parties to get closer to the median voter outcome.

In equilibrium, parties propose policies that are equidistant from the median voting outcome. Given that voters' preferences over $\delta$ are symmetric, the voter who is indifferent between the two proposed policies is in fact the median voter, which in turn implies that both parties have the same probability of winning the election, with each party's membership comprising

\footnotetext{
${ }^{3}$ The results with different values of $\alpha_{p}$ are available upon request from the authors. See also the Annex for the impact of modifying $\alpha_{p}$ on a calibrated version of this model.
} 
exactly one half of the population. Moreover, with the proposed policies equidistant from the median outcome, and with each party having a $50 \%$ chance of winning the election, the expected policy is equal to the median voting outcome.

Although this symmetry in the results is clearly linked to the symmetry of individual preferences, it does not depend on the symmetry in the distribution of types. ${ }^{4}$ Table 2 presents the EPWE when the distribution of income $^{5}$ is positively skewed, producing equilibrium policy choices that are also equidistant from the median voting outcome as in Table 1. Comparing with Table 1, we see that the positive skewness of the income distribution induces both parties to propose more social insurance in equilibrium. The intuition for this result is that increasing the positive skewness of the income distribution increases the proportion of people benefiting from the income redistribution associated with social insurance.

Table 2: Equilibrium with positively skewed income distribution and uniformly distributed risk

\begin{tabular}{|c|c|c|c|c|c|}
\hline$\eta$ & $\Delta$ & $\delta^{L}$ & $\delta^{R}$ & $\delta_{m}$ & $\delta^{U}$ \\
\hline 0.1 & 0.03 & $82.17 \%$ & $27.19 \%$ & \multirow{3}{*}{$54.68 \%$} & \multirow{3}{*}{$41.68 \%$} \\
\hline & 0.01 & $64.65 \%$ & $44.84 \%$ & & \\
\hline & 0.001 & $55.68 \%$ & $53.65 \%$ & & \\
\hline 0.3 & 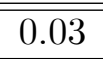 & 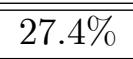 & 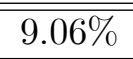 & \multirow{3}{*}{$18.23 \%$} & \multirow{3}{*}{$13.89 \%$} \\
\hline & 0.01 & $21.55 \%$ & $14.95 \%$ & & \\
\hline & 0.001 & $18.56 \%$ & $17.88 \%$ & & \\
\hline 0.5 & $\bar{~} 0.03$ & $16.44 \%$ & $5.44 \%$ & \multirow{3}{*}{$10.94 \%$} & \multirow{3}{*}{$8.34 \%$} \\
\hline & 0.01 & $12.93 \%$ & $8.97 \%$ & & \\
\hline & 0.001 & $11.14 \%$ & $10.73 \%$ & & \\
\hline
\end{tabular}

Moreover, the equilibrium outcome depends on the whole distribution of income and risks, and not only on the average and median values as with the median voter outcome. Table 3 reports results for the cases where risks are uniformly distributed as in Table 1, but where income is distributed according to a $\operatorname{Beta}(2,2)$ distribution. This distribution has the same average and median income as the uniform distribution in Table 1, but is less polarized in the sense that the probability mass at the tails is shifted to the center.

Table 3 suggests that when the income distribution becomes less dispersed, both parties propose higher insurance coverage. ${ }^{6}$ This result may

\footnotetext{
${ }^{4}$ Roemer(2001, Example 3.2) exhibits the same symmetry of Wittman equilibria, but in a simpler model in which each party maximizes the utility of an exogenously chosen representative member. This symmetry also holds for any distribution of types in his model.

${ }^{5}$ Table 2 gives results with a $\operatorname{Beta}(2,5)$ distribution of income over $[0,4]$, with risks independently and uniformly distributed over $[0,2 / 3]$.

${ }^{6}$ This result is robust to several mean-preserving spreads of the income distribution. We obtain similar results for all symmetric $\operatorname{Beta}(x, x)$ distributions of income with $x>1$
} 
strike as bizarre since a less dispersed income distribution reduces the fraction of both poor and rich voters, who have strictly opposite preferences. As already noted, each voter's preference over social insurance depends only on her own income and risk relative to the mean values, so that it is unaffected by mean-preserving changes of the income and risk distribution. However the type distribution and in particular the median type will change. Comparison of Table 1 and 3 shows that the median preference $\delta_{m}$ increases as the income distribution becomes less polarized.

Table 3: Equilibrium with symmetric and unimodal income distribution and uniformly distributed risk

\begin{tabular}{|c|c|c|c|c|c|}
\hline$\eta$ & $\Delta$ & $\delta^{L}$ & $\delta^{R}$ & $\delta_{m}$ & $\delta^{U}$ \\
\hline 0.1 & 0.03 & $69.16 \%$ & $22.7 \%$ & \multirow{3}{*}{$45.93 \%$} & \multirow{3}{*}{$41.68 \%$} \\
\hline & 0.01 & $54.21 \%$ & $37.67 \%$ & & \\
\hline & 0.001 & $46.77 \%$ & $45.07 \%$ & & \\
\hline 0.3 & 0.03 & $23.05 \%$ & $7.57 \%$ & \multirow{3}{*}{$15.31 \%$} & \multirow{3}{*}{$13.89 \%$} \\
\hline & 0.01 & $18.08 \%$ & $12.56 \%$ & & \\
\hline & 0.001 & $15.59 \%$ & $15.03 \%$ & & \\
\hline 0.5 & 0.03 & $13.84 \%$ & $4.54 \%$ & \multirow{3}{*}{$9.19 \%$} & \multirow{3}{*}{$8.34 \%$} \\
\hline & 0.01 & $10.84 \%$ & $7.54 \%$ & & \\
\hline & 0.001 & $9.35 \%$ & $9.02 \%$ & & \\
\hline
\end{tabular}

Figure 1 is useful to understand the reason for this result. Consider that income polarization is reduced by a mean-preserving reduction in the income spread (removing the richest and the poorest individuals from the uniform income distribution). It is clear from Figure 1 that all richest individuals are below median type while not all the poorest individuals are above the median type. This asymmetry implies that the median type will increase as we remove the richest and the poorest individuals from the population. This shifts up the equilibrium policy choices of both parties. When the reduced dispersion of income takes the form of a shifting of probability mass from the extremes to the centre (as between Tables 1 and 3), then the distribution of preferences within each party will change with a shift of the center of gravity towards the median voter outcome. At the same time the median type will increase following the same argument as for the reduction of the income spread.

Figure 2 shows the parties' reaction functions $\left(\delta^{L}\left(\delta^{R}\right)\right.$ and $\left.\delta^{R}\left(\delta^{L}\right)\right)$, and how they are affected when the income distribution becomes less polarized. We find that reduced income polarization shifts both reaction functions outward, which leads both parties to propose a higher coverage in equilibrium. It is worth noting that the parties's reaction curves display strategic complementarity. Indeed, fixing $\delta^{L}$, an increase in $\delta^{R}$ (with $\delta^{R}<\delta^{L}$ ) will induce

(we report results only for the distribution $\operatorname{Beta}(2,2)$ in Table 3 ), and also for the uniform distribution with mean-preserving changes of the income spread, as suggested by a referee. 
(border) members of party $L$, who want less social insurance, to switch to party $R$. In response, party $L$ will now support more social insurance. Hence the driving force of the strategic complementarity in the political competition game is the endogenous memberships.

\section{[Insert Figure 2 about here]}

Finally, we compare the EPWE coverage rates with their Rawlsian and utilitarian levels. The Rawlsian social coverage rate maximizes the welfare of the worst-off individual, who is clearly the one with the lowest income $\underline{w}$ and the highest risk $\bar{\theta}$. That is $\delta^{\text {Rawls }}=\delta^{*}(t(\underline{w}, \bar{\theta}))$. Since the demand for social insurance decreases with income and increases with risk, the worst-off individual will demand higher coverage than anyone else in either party, so we have that $\delta^{\text {Rawls }}>\delta^{L}>\delta_{m}>\delta^{R}$. Moreover, we obtain from equation (9) that the Rawlsian outcome is

$$
\delta^{\text {Rawls }}=\left\{\begin{array}{lr}
\frac{1}{2 \eta}\left[\frac{\bar{\theta}}{\theta_{\mu}} \frac{w_{\mu}}{\underline{w}}-1\right] & \text { for } t(\underline{w}, \bar{\theta})<\bar{t} \\
1 & \text { for } t(\underline{w}, \bar{\theta}) \geq \bar{t}
\end{array}\right.
$$

Observe that $t(\underline{w}, \bar{\theta})=\bar{\theta} / \underline{w}$ because the highest risk gets efficient insurance on the private market so $\varphi(\alpha, \bar{\theta})=0$. It follows that $t(\underline{w}, \bar{\theta})>\underline{t} \equiv \theta_{\mu} / w_{\mu}$ and thus $\delta^{\text {Rawls }}>0$. Equation (11) shows that the worst-off individual prefers full social insurance if the distortion parameter $\eta$ is low enough. Finally, note that if the lowest income is small enough, as in our simulations above, then $t(\underline{w}, \bar{\theta})>\bar{t}$ and the Rawlsian criterion calls for full social insurance since the poorest individual does not contribute much to the financing of social insurance.

We now turn to the utilitarian outcome. The utilitarian planner maximizes the average utility in the population,

$$
W(\delta)=\int_{\underline{w}}^{\bar{w}} \int_{\underline{\theta}}^{\bar{\theta}} v(\delta, w, \theta) h(w, \theta) d w d \theta
$$

where $v(\delta, w, \theta)$ is given by equation (6). The first-order condition is

$$
\frac{\partial W(\delta)}{\partial \delta}=-\theta_{\mu}(1+2 \eta \delta)+E[\theta(1+\varphi(\alpha, \theta)],
$$

where $E[$.$] denotes the expectation operator. The utilitarian coverage is$ given by

$$
\delta^{U}=\frac{1}{2 \eta}\left[\frac{E[\theta \varphi(\alpha, \theta)]}{\theta_{\mu}}\right] .
$$

Therefore the utilitarian coverage is independent of the income distribution. The reason is that, with the dual approach of choice under risk, the utility function is linear in income and so all individuals exhibit the same 
marginal utility of income. The utilitarian government has no income redistribution motive, and its optimal policy choice trades off the efficiency gain from social insurance against the distortion cost.

A corollary to this result is that modifying the income distribution without changing the distribution of risks will not change the utilitarian outcome. Tables 1 to 3 display the same utilitarian social insurance rates, which are reported in the last column. On the other hand, such a change in the income distribution will definitely affect the EPWE coverage rate, as can be seen by comparing the results in Tables 1 to 3 . We now compare the utilitarian outcome (12) with the median voter outcome $\delta_{m}$. Both are equivalent if and only if

$$
\frac{E[\theta(1+\varphi(\alpha, \theta)]}{w_{\mu}}=\operatorname{Med}\left[\frac{\theta(1+\varphi(\alpha, \theta))}{w}\right],
$$

where Med[.] denotes the median operator. It is clear that, in general, this condition does not hold and so $\delta_{m} \neq \delta^{U}$. However the condition is satisfied in the special case considered in Table 1 where income and risks are independently and uniformly distributed. The values of $\delta_{m}$ reported in Table 1 thus correspond to the utilitarian social rates. This is not the case anymore when $w$ is not uniformly distributed, as in Tables 2 and 3. We rather obtain in these two cases that $\delta_{m}>\delta^{U}$ - i.e., that the expected Wittman social coverage exceeds the utilitarian coverage.

\section{Conclusion}

In this paper, we have analyzed the political support for social insurance when individuals can buy additional insurance on the private market. Social insurance is financed by a distortionary income tax and redistributes across income and risk levels. Private insurance is impaired by adverse selection, which translates into suboptimal coverage rates. Using the dual theory of choice under risk, we have shown that the multi-dimensional types can be aggregated into a single dimensional type function reflecting income and risk differences. Individuals can then be ranked into a transitive order according to this type aggregator. Those with lower income and higher risk prefer more social insurance.

The political equilibrium model we have used differs from the classical Downsian one. We assume that political parties care about policy as well as about winning election, and that elections are inherently uncertain. When choosing their platforms, parties take into account both the utility their members would get from their proposition in case they win and the probability of winning the elections with this platform. We model party preferences as endogenous, with the requirement that, at equilibrium, each party maximizes the utility of its members, and each individual chooses freely her party membership based on what policies parties offer. 
We calculate the endogenous parties Wittman equilibrium for different parameters values and obtain the following results. We first show that more electoral uncertainty and less risk aversion lead to more policy differentiation. If electoral uncertainty is not too high, equilibrium platforms are both interior and the equilibrium is symmetrically distributed around the median voter outcome. In that case, the median type is indifferent between the parties' proposals, each party ties for winning and the expected implemented policy is the Condorcet winner. This symmetry does not depend on the symmetry of the income distribution function, since it carries over to positively skewed distributions. Increasing the (positive) skewness of the income distribution leads both parties to propose more social insurance. The equilibrium policy choices depend on the whole income distribution and not only on the median and mean values as in the Downsian model. A less polarized income distribution also increases the equilibrium social insurance rates. Finally, we compare the political equilibrium outcome with the Rawlsian and utilitarian outcomes. The Rawlsian criterion always calls for a larger social insurance rate than what any political party would propose in equilibrium. The utilitarian outcome can recommend either more or less social insurance than the political equilibrium outcome.

To conclude we think that the endogenous Wittman equilibrium deserves further analysis. We provide in the appendix a first try at calibrating this model with real data, using U.S. data from the PSID survey. Obviously, much remains to be done empirically. We hope this paper convinces readers that the Wittman model should be tested in many more economic situations to check whether it provides a good representation of the political outcome. To paraphrase Roemer (2005), "We can learn a good deal from simulation, and this allows us to work with models in which both the economic and political sides are reasonably complex. These methods have, thus far, barely been touched in political economy, but I expect them to come into their own in the coming years." It would be especially interesting to extend the Wittman equilibrium concept to more than two parties. 


\section{Appendix : Model calibration}

We first describe how we have used data from the Panel Study of Income Dynamics (PSID) to gather information on income levels and health expenditures for a sample of 6863 households. We then calibrate our model to calculate the Wittman equilibrium.

\section{A.1. Distribution of risk and income}

To calibrate our model, we need information on both income and risk distributions. The unit of observation is the household. As a measure of income, we use the 1998 total family income as reported in the 1999 "Income plus" PSID data base (variable Faminc99). This variable measures the sum of taxable income of head and wife, transfer income of head and wife, taxable and transfer incomes of other family unit members, and social security income. Among respondents to this question, the average family income is $\$ 52,200$ and the median income is $\$ 38,300$.

As for risks, we concentrate on medical care costs. We first gather information on medical care costs incurred by these families in 1999 and 2000. These costs are obtained from the 2001 "Core family data" (variable ER19860) and consist of out-of-pocket costs plus the costs covered by Medicare, Medicaid, or other health insurance. The events covered are hospital and nursing home stays, doctor and clinic visits, outpatient surgery, dental visits, prescriptions, and in-home medical care. We obtain the following distribution of medical care costs.

Table 4: Distribution of medical care costs in 1999 and 2000

\begin{tabular}{|l|r|}
\hline less than $1,000 \$$ & $15.60 \%$ \\
\hline $1,000-5,000 \$$ & $31.00 \%$ \\
\hline $5,000-25,000 \$$ & $34.60 \%$ \\
\hline $25,000-100,000 \$$ & $9.45 \%$ \\
\hline $100,000-500,000 \$$ & $1.50 \%$ \\
\hline more than $500,000 \$$ & $0.25 \%$ \\
\hline no response & $7.60 \%$ \\
\hline
\end{tabular}

We keep in our database the 6863 households who have answered both questions (on income and health costs). We are not directly interested in the health costs, but in the risk to incur such costs. Our model uses a binary description of events (damage or no damage) while the PSID gives us some information on the size of the damage. To calibrate our model, we consider that a damage occurs if household medical care costs in 1999 and 2000 are greater than a threshold. We consider two distinct thresholds: 5,000 $\$$ and $25,000 \$$. For the low threshold, $45.8 \%$ of households have incurred a damage, and this proportion is $11.2 \%$ for the high threshold.

We know each household's 1998 income and whether it has incurred a damage in 1999 and 2000. We then translate this binary information into a probability in 1998 to incur the damage in the following years. We compute, 
for each percentile of the income distribution, the proportion of households incurring the damage. This proportion is then used as the proxy for the risk probability of all households in this income group. The joint distribution of risk and income we obtain exhibits a correlation between income and risk of -0.10 for the low cost definition and 0.08 for the high one.

\section{A.2. Political equilibrium}

Given the discrete distribution of risk and income we cannot use the first-order approach to calculate the Wittman equilibria. We briefly explain the algorithm used before reporting our results.

We exploit the feature of the symmetric equilibrium in which both parties pick a policy equidistant from the population median. ${ }^{7}$ Formally, for each coverage rate $\delta^{L}$ proposed by the Left party we calculate the coverage rate $m\left(\delta^{L}\right)$ for the Right party that makes the median voter indifferent. The function $m\left(\delta^{L}\right)$ solves

$$
v\left(\delta^{L}, t_{m}\right)=v\left(m\left(\delta^{L}\right), t_{m}\right)
$$

where $t_{m}$ is the median type. Thus we have

$$
m\left(\delta^{L}\right) \leq \delta_{m} \leq \delta^{L},
$$

where $\delta_{m}$ denotes the policy most favored by the median type (i.e., the Condorcet winner). We then use the following algorithm: (1) Start with $\delta^{L}=\delta_{m}+\varepsilon$ for $\varepsilon>0$ small. (2) Compute $\delta^{R}=m\left(\delta^{L}\right)$. (3) Verify that the left party has no incentive to deviate. That is, study small deviations around $\delta^{L}$ and compute the impact on the probability of winning the elections and on the average utility of its members. If all small deviations around $\delta^{L}$ have effects of opposite signs on the winning probability and on the membership's utility, the EPWE has been found ${ }^{8}$ and the procedure stops. If not, we increase slightly the value of $\delta^{L}$ and go back to (2).

Using this algorithm, we have calculated the equilibrium policy pair for different values of the parameters. Table 4 summarizes the results we obtain with the two definitions of the damage and with two values for the political risk aversion parameter $\alpha_{p}$.

We obtain intuitively that the equilibrium outcome moves closer to the Condorcet winner as political risk aversion increases. Comparing the results obtained with the two definitions of the damage, we see that the Condorcet winning coverage rate decreases when the damage is high, but the policy proposed by the left party actually increases! This is due to the differing risks distribution when one moves from one definition of the damage to the other.

\footnotetext{
${ }^{7}$ Equivalently this means that at equilibrium party $L$ 's membership is composed of all types lower than the median type and party $R$ of all types above the median. Hence, each party has a $50 \%$ chance of winning the elections at equilibrium.

${ }^{8}$ We check that, if party $L$ has no incentive to deviate, this is also the case for party $R$.
} 
Table 5: EPWE with PSID data (with $\alpha=0.05, \eta=0.4, \Delta=0.1$ )

\begin{tabular}{|l|l|l|l|}
\hline$\alpha_{p}$ & $\delta^{L}$ & $\delta^{R}$ & $\delta_{m}=E\left(\delta^{L}, \delta^{R}\right)$ \\
\hline \multicolumn{4}{|l|}{ Low damage } \\
\hline 0 & $56.7 \%$ & $39.3 \%$ & $48 \%$ \\
\hline 0.05 & $55.9 \%$ & $40.1 \%$ & $48 \%$ \\
\hline \multicolumn{4}{|l|}{ High damage } \\
\hline 0 & $62.8 \%$ & $12.4 \%$ & $37.6 \%$ \\
\hline 0.05 & $60.8 \%$ & $14.4 \%$ & $37.6 \%$ \\
\hline
\end{tabular}

Acknowledgments. This paper is a major revision of our working paper previously circulated under the title "Policy-oriented parties and the choice between social and private insurance". This research was supported by the Belgian French community grant "Heterogeneity in social organizations" (ARC 05/10-331). This paper has been presented at the First Workshop of the RTN Project on Financing Retirement in Europe (Barcelona), Third Health Economics Workshop (Marseille) and at seminars held at Universidad Autónoma Barcelona, Universidad Pompeu Fabra and Toulouse. We wish to thank especially Jean-Charles Rochet, Paula Lopes, John Roemer and three anonymous referees for their comments. All remaining errors are ours.

\section{References}

[1] Alesina, A., Rosenthal, H., 1995. Partisan Politics, Divided Government, and the Economy. Cambridge University Press, Cambridge, MA.

[2] Baron, D., 1993. Government formation and endogenous parties. American Political Science Review 87, 34-47.

[3] Blomqvist, A., Horn, H., 1984. Public health insurance and optimal income taxation. Journal of Public Economics 24, 352-71.

[4] Caplin, A., Nalebuff, B., 1997. Competition among institutions. Journal of Economic Theory 72, 306-342.

[5] Cremer, H., Pestieau, P., 1996. Redistributive taxation and social insurance. International Tax and Public Finance 3, 281-95.

[6] De Donder, Ph., Hindriks, J., 2003. The politics of redistributive social insurance. Journal of Public Economics 87, 2639-2660.

[7] Downs, A., 1951. An Economic Theory of Democracy. Harper Collins, New York.

[8] Gouveia, M. , 1997. Majority rule and the public provision of a private good. Public Choice 93, 221-44. 
[9] Hofferbert, R., Budge, I., 1992. The party mandate and the Westminster model: election programmes and government spending in Britain. British Journal of Political Sciences 22, 151-182.

[10] Hofferbert, R., Klingemann, H., 1990. The policy impact of party programs and government declarations in the Federal Republic of Germany. European Journal of Political Research 18, 277-304.

[11] MacDonald, S. E., Listhaug, O., Rabinowitz, G., 1991. Issues and party support in multiparty systems. The American Political Science Review $85,1107-1131$.

[12] Mailath, G., 1987. Incentive compatibility in signalling games with a continuum of types. Econometrica 55, 1349-1365.

[13] Ortuño-Ortín, I., Roemer, J., 2000. Endogenous formation and the effect of income distribution on policy. Working Paper 2000-06, Instituto Valenciano de Investigaciones Económicas, Valencia.

[14] Petretto, A., 1999. Optimal social health insurance with supplementary private insurance. Journal of Health Economics 18, 727-45.

[15] Poole, K., Rosenthal, H., 1984a. The polarization of american politics. Journal of Politics 46, 1061-1079.

[16] Poole, K., Rosenthal, H., 1984b. US presidential elections 1968-1980: A spatial analysis. American Journal of Political Science 35, 228-278.

[17] Rochet, J.-C, 1991. Incentives, redistribution and social insurance. The Geneva Papers on Risk and Insurance Theory 16, 143-65.

[18] Roemer, J., 2001. Political Competition. Theory and Applications. Harvard University Press, Cambridge, MA.

[19] Roemer, J, 2005. Distribution and politics: a brief history and prospect. Social Choice and Welfare 25, 507-525.

[20] Roemer, J, 2007. Modeling party competition in general elections. Forthcoming in: Weingast, B., Wittman, D. (Eds.), Oxford Handbook of Political Economy. Oxford University Press, Oxford.

[21] Wittman, D., 1973. Parties as utility maximizers. American Political Science Review 67, 490-498.

[22] Yaari, M., 1987. The dual theory of choice under risk. Econometrica $55,95-115$. 